www.jmscr.igmpublication.org

Impact Factor (SJIF): 6.379

Index Copernicus Value: 71.58

ISSN (e)-2347-176x ISSN (p) 2455-0450

crossref DOI: _https://dx.doi.org/10.18535/jmscr/v6i3.184

\title{
Journal Of Medical Science And Clinical Research

\section{Comparative Study of the Effect of Oral Omeprazole with Oral Ranitidine on pH and Volume of Gastric Aspirate in Patients Undergoing Elective Surgery}

Author

\author{
Dr GANGA, G MD, DA
}

Associate Professor, Department of Anaesthesiology, Government Medical College, Kottayam

\begin{abstract}
Background: The risk of regurgitation and vomiting with subsequent pulmonary aspiration of gastric contents has been recognized as a serious hazard. Various pharmacological agents are being used to minimize the risk of acid aspiration.

The objectives of this present study are to compare the efficacy of omeprazole and ranitidine in reducing the volume of gastric fluid and to compare the efficacy of omeprazole and ranitidine in increasing the $p H$ of gastric fluid in patients undergoing elective surgery.

Material and Methods: After Obtaining institutional approval and individual consent 60 patients were randomly selected into III groups of 20 each in the randomized comparative study. The group I as control, group II received 40mg omeprazole and III received $150 \mathrm{mg}$ ranitidine night before and 6am on the day of surgery. All the patients were given premedication of injection phethidine $1 \mathrm{mg} / \mathrm{kg}$. General anesthesia is induced and when a steady state is achieved an 18 FG nasogastric tube well lubricated with ligonocane jelly is passed in to the stomach. Volume of gastric fluid and PH of the aspirate is collected using $20 \mathrm{ml}$ syringe and $\mathrm{pH}$ measured by $\mathrm{pH}$ paper.

Result: The patients characteristics and demographic data were comparable in the 2 groups. It is proved beyond doubt that both the treatment groups were definitely superior to the control group in increasing the gastric PH and as well as reduce the gastric volume.

Conclusion: The omeprazole group is found to be effective adjuvant to safe anesthesia practice. It should be routinely included in pre anesthetic preparation of all elective surgery patients under general anesthesia to prevent the dreaded complication of acid aspiration pneumonitis
\end{abstract}

Keywords: Omeprazole, Ranitidine, Gastric aspirate.

\section{Introduction}

The majority of anaesthesiologist are probably unaware of the potentially dangerous amount of gastric contents which may be in the stomach of normal prepared in patients waiting induction of anaesthesia for elective surgery of any nature. This can trap the unwary anasthesiologist into tragic situation of acid aspiration syndrome. The risk of regurgitation and vomiting with subsequent pulmonary aspiration of gastric content has been recognized as a serious hazard.

Acid aspiration is an important complication of obstetric anaesthesia with a potentially catastrophic result. In 1946 Curtis Mendelson ${ }^{1}$ described 66 cases in which gastric contents has been regurgitated and initiated the syndrome which now bears his name. 
The risk of pulmonary aspiration increases progressively as the $\mathrm{pH}$ of the aspirate $<2.5$ and volume $>25 \mathrm{ml}$ which may cause widespread damage to parenchyma of the $\operatorname{lung}^{2}$. To eliminate the problems of aspiration pneumonitis by increasing the $\mathrm{pH}$ and decreasing the volume of gastric contents various pharmacological and non pharmacological methods have been tried.

The non pharmacological methods to decrease the volume is restrict oral intake and empty the stomach by physical means. Pharmacological methods which decreases gastric fluid volume is metoclopramide which hasten the gastric emptying and ${ }^{3}$ anticholinergics which decreases gastric fluid volume inhibiting the production of gastric fluid. We can use non particular antacids like sodium citrate to decrease gastric $\mathrm{pH}$. Orally administered antacids not adequately mix with gastric fluid due to division into two sacs (Holdworth 1980) ${ }^{4}$

In the present study the effect of omeprazole and ranitidine on gastric fluid volume and $\mathrm{PH}$ on patients for elective surgery under general anaesthesia has been compared.

\section{Material and Methods}

Approval from Ethics Committee was obtained prior to the start of the study. This is a case comparative study in patients undergoing elective surgery in Medical Collage Kottayam during the study period will be consider as the population for the study. The patients between age group 20-65 yrs, both males and females belong to ASA physical status I were chosen for study. Total sample size is estimated as 60 with 20 samples in each group.

All patients were thoroughly examined and only ASA physical status I patients were included. All patients with active oesophageal or peptic ulcer disease, pyloric stenosis and those receiving antisecretory drugs were excluded from the study.

The study was conducted in twenty patients each in control group omeprazole and ranitidine groups.

Group I: Patients belong to this group received only injection pethidine $1 \mathrm{mg} / \mathrm{kg}$ body weight intramuscularly 1 hour before study. They were considered as the control group.
Group II: Patients belonging to this group received cap. Omeprazole $40 \mathrm{mg}$ at $20.00 \mathrm{hrs}$. on the evening before surgery and $40 \mathrm{mg}$ at $6.00 \mathrm{am}$ on the morning of surgery. They also received a premedication of inj. Pethidine $1 \mathrm{mg} / \mathrm{kg}$ body weight intramuscularly 1 hour before surgery.

Group III: Patients belonging to this group received. $\mathrm{T}$. ranitidine $150 \mathrm{mg}$ at 20.00 hours on the night before surgery and $\mathrm{T}$. ranitidine $150 \mathrm{mg}$ orally at $6.00 \mathrm{am}$ on the morning of surgery. They also received a premedication of Inj. Pethidine $1 \mathrm{mg} / \mathrm{kg}$ body weight intramuscularly 1 hour before surgery.

All patients were visited the previous evening and a detailed preoperative assessment as detailed in the proforma was performed. Informed consent of the patients were obtained. Patients were instructed to take the tables according to the study group. All patients were premedicated with Inj. Pethidine $1 \mathrm{mg} / \mathrm{kg}$ body weight 1 hour before surgery.

Intravenous cannulation was done with $18 \mathrm{G}$ canula in a peripheral vein in the upper limb and a normal saline infusion started. General anaesthesia is induced. After a steady state was achieved an 18 FG nasogastric tube well lubricated with lignocaine jelly was passed through the nostril into the stomach. Location of tube was confirmed by air insufflation and auscultation of the upper abdomen.

\section{Method of Statistical analysis}

In this present study the data collected with a master sheet and statistical tables were constructed. The statistical hypothesis formulated were tested statistically by using $^{6} \chi^{2}$, tests on the qualitative data and student ' $\mathrm{t}$ ' test in the case of quantitative data for testing equality of mean values. In order to predict the interval in which $95 \%$ of the $\mathrm{pH}$ values may be the $95 \%$ confidence interval was computed. Diagram and charts were drawn wherever necessary to substantiate the important findings. All statistical computation were done with the help of SPSS computer package. 


\section{Results}

Table-1 Demographic data

Mean \pm SD of age of patients in group 1/11/111

\begin{tabular}{|l|c|c|c|c|}
\hline Group & $\mathrm{n}$ & Age (in year) & $\mathrm{t}$ value & $\mathrm{p}$ value \\
\hline I Control & 20 & $39.95 \pm 10.30$ & - & - \\
\hline II Omiprezole & 20 & $38.0 \pm 9.39$ & 0.337 & $\mathrm{p}>.05$ \\
\hline III Rantitidine & 20 & $38.5 \pm 11.17$ & 0.456 & $\mathrm{p}>.05$ \\
\hline
\end{tabular}

No significant difference in the study groups

Table 2: $\mathrm{pH}$ value

Mean \& S.D of $\mathrm{pH}$ value in Group I/II/III and level of significance

\begin{tabular}{|l|c|c|c|c|}
\hline \multirow{2}{*}{ Group } & \multicolumn{2}{|c|}{$\mathrm{pH}$ value } & \multirow{2}{*}{ t value } & \multirow{2}{*}{$\mathrm{p}$ value } \\
\cline { 2 - 3 } & Mean & $\mathrm{SD}$ & & \\
\hline I & 1.55 & 0.5104 & - & - \\
\hline II & 7.6 & 0.5026 & 37.77 & $\mathrm{P}<.0001$ \\
\hline III & 6.55 & 0.5104 & 3098 & $\mathrm{P}<.0001$ \\
\hline
\end{tabular}

Group II Vs Group III; $\mathrm{t}=6.555 ;$ d.f $=38 ; \mathrm{P}<.001$

In the present study the effectiveness of the methods administered was assessed by comparing the mean $\mathrm{pH}$ value. In the control group, it is only 1.55 whereas a fivefold increased mean value was observed in group II. (Omeprazole). Even in the case of ranitidine group the $\mathrm{pH}$ value was rather high $($ mean $=6.55)$. The difference between the control value and group II and group III was tested statistically by using student ' $\mathrm{t}$ ' test and was find significant at a very high level $(\mathrm{P}<0.00001)$. Thus it is established beyond doubt that omeprazole and ranitidine were definitely superior to control in increasing the $\mathrm{pH}$ value.

Since group II and group III happen to be superior to group I. It is further compared to establish which one of these two treatment methods out ways the other in the effectiveness. It is further tested statistically the mean $\mathrm{pH}$ value of group II with group III. Even then the difference was found to be highly significant $(\mathrm{t}=6.555, \quad \mathrm{df}=38, \quad$ PO.001 $)$ statistically. In other words while considering group II \& III, II is more effective in $\mathrm{pH}$ value thawgroup III (diagram).
Table 3 : Volume

Mean \& s.d of Volume in Group 1/11/111 and level of signification

\begin{tabular}{|c|c|c|c|c|}
\hline \multirow[t]{2}{*}{ Group } & \multicolumn{2}{|c|}{ Volume(m) } & \multirow{2}{*}{$\begin{array}{c}\mathrm{T} \\
\text { Value }\end{array}$} & \multirow{2}{*}{$\begin{array}{c}\mathrm{P} \\
\text { value }\end{array}$} \\
\hline & Mean & SD & & \\
\hline I & 33.75 & 5.8 & - & - \\
\hline II & 5.45 & 1.43 & 21.12 & $\mathrm{P}<.0001$ \\
\hline III & 10.35 & 1.63 & 17.33 & $\mathrm{P}<.0001$ \\
\hline
\end{tabular}

Efforts were made to compare the mean volume after the treatment was given in all the three groups. In the control group the mean value was $33.75 \mathrm{ml}$ in place of only $5.45 \mathrm{ml}$ in group II Even in group III it was 2 times higher compared to group II (mean=5.45). The difference in the mean volume between the three groups was tested statistically was found highly significant (PO.0001). Thus it is observed that group II and III are better than group I in reducing the volume. As in the case of $\mathrm{pH}$ value the mean volume obtained in group II was compared with group III. In this case in group III it was $10.35 \mathrm{ml}$ whereas it was only $5.4 \mathrm{ml}$ in group II. Even in this case the statistical test for equality of mean values happen to be highly statistically significant (PO.0001). Thus it is concluded that omeprazole is far superior to ranitidine not only in increasing the $\mathrm{pH}$ value but also to reduce the volume.

Table 4: 95\% (Confidence interval)

$95 \%$ confidence interval of $\mathrm{pH} /$ volume in group II/Group III

\begin{tabular}{|l|c|c|}
\hline \multirow{2}{*}{ Group } & \multicolumn{2}{|c|}{$95 \%$ Confidence interval } \\
\cline { 2 - 3 } & $\mathrm{pH}$ & Volume \\
\hline II & $7.6 \pm 0.22$ & $5.45 \pm 0.63$ \\
\hline III & $6.5 \pm 0.22$ & $1.35 \pm 0.71$ \\
\hline
\end{tabular}

Since it is noted that omeprazole and ranitidine were effective in increasing the $\mathrm{pH}$ value it is attempted to predict a possible range in which $95 \%$ of the values may lie. Then regarding $\mathrm{pH}$ value if omeprazole was administered the $\mathrm{pH}$ value may lie in the interval 7.38 to 7.82 . At the same time in the case of ranitidine the $95 \%$ Confidence interval will be 6.28 to 6.72 . Similarly the mean volume was predicted as 4.82 to 6.08 in group II and 9.64 to $11.06 \mathrm{ml}$ in group III. 


\section{Discussion}

Aspiration of gastric contents during anaesthesia is a preventable iatrogenic complication. Hence attention has been focussed on prophylactic pharmacologic approaches to reduce the risk of pulmonary injury associated with aspiration of gastric contents. The studies by Mendelson and Teabeaut showed that a $\mathrm{pH}<2.5$ and volume of gastric contents $>25 \mathrm{ml}$ was necessary to produce the clinical features of aspiration pneumonitis. These values have been generally accepted as the critical level to be avoided.

The study was conducted in sixty ASA physical status I patients undergoing elective surgery. They were randomly allocated into three groups group I patients received no medication and served as control group. GroupII patients received omeprazole $40 \mathrm{mg}$ orally the night before surgery and $40 \mathrm{mg}$ on the morning of surgery at 6.00 AM. Group III patients received ranitidine $150 \mathrm{mg}$ orally at night before surgery and $150 \mathrm{mg}$ orally on the morning of surgery. All patients were premedicated with pethidine $1 \mathrm{mg} / \mathrm{kg}$ body weight has 1 hour before surgery. All patients received a standard anaethesia technique and after a steady state was achieved an 18FG nasogastric tube well lubricated with xylocaine jelly was passed through the nostril and using a $20 \mathrm{ml}$ syringe. Volume of gastric fluid aspirated and $\mathrm{pH}$ measured by $\mathrm{pH}$ paper.

Manchikanti L (1984) ${ }^{5}$ demonstrated in untreated control patients undergoing elective-surgery a gastric $\mathrm{pH}<2.5$ in $75 \%$ patients andin $40 \%$ a volume $>20 \mathrm{ml}$. In the present study, the control group $\mathrm{pH}$ value ranged from 1-2 with a mean of 1.55. The volume of gastric aspirate in the control group ranged from $25-48 \mathrm{ml}$ with a mean of $33.7 \mathrm{ml}$. Here $90 \%$ of patients had $\mathrm{pH}<2.5$ and volume $>25 \mathrm{ml}$.

Ranitidine is a highly selective $\mathrm{H} 2$ receptor antagonist which is 5-8 times potent than cimetidine on a molar basis. It is rapidly absorbed after oral administration, achieveing peak plasma levels in 6090 minutes with therapeutically effective concentrations lasting for atleast 8 hours. Various studies have shown that ranitidine by various modes of administration strikingly reduced gastric acidity with a modest to marked reduction in gastric volume (Manchikanti ${ }^{5}$ L 1984,1986). Bertaccini et al $(1981)^{6}$ has claimed that ranitidine increased the lower oesophageal sphincter tone in animals. Buock-Utne $^{7}$ et al(1984) has shown that ranitidine increased the mean lower oesophageal sphincter pressure by $21.2 \mathrm{~cm} \mathrm{H}_{2} 0$. Intravenous ranitidine significantly increased the barrier pressure. So they have recommended ranitidine which increased gastric $\mathrm{pH}$ and increases the lower oesophageal sphincter tone prior to induction of anaesthesia in patients at risk of developing oesophageal reflux

In the present study the group of patients receiving $\mathrm{T}$. ranitidine $150 \mathrm{mg}$ orally in the night before surgery and $150 \mathrm{mg}$ orally in the morning of operation showed that the gastric $\mathrm{pH}$ ranged from 67 with a mean $\mathrm{pH}$ of 6.55 . The gastric volume range from $8-13 \mathrm{ml}$ with a mean of $10.35 \mathrm{ml}$.

Lamer et al (1985) showed that maximal inhibition of gastric acid secretion occurred 6 hours after a single dose of $40-80 \mathrm{mg}$ omeprazole. Lind et al (1985) ${ }^{8}$ found that in normal subjects maximum inhibition of pentagastrin stimulated gastric acid secretion occurred 1 hour after administration of omeprazole. Lind et al(1985) ${ }^{8}$ also demonstrated that omeprazole is a gastric proton pump inhibitor which inhibited pentagastrin stimulated acid secretion in man.

Omeprazole is effective in the treatment of acidrelated gastrointestinal diseases. Repeated administration of omeprazole has a cumulative effect on acid inhibition and more effective in increasing intragastric $\mathrm{pH}$ than a single dose. Daily oral dose of $20 \mathrm{mg}$ and higher showed a consistent and effective acid control. Prichard ${ }^{9}$ et al (1985) and Ching $^{10}$ et al (1986) showed an animal studies that there was no evidence of foetal toxicity and teratogenicity.

Patients given omeprazole showed a gastric $\mathrm{pH}$ range between 6-8 with a mean of 7.6. There is a fivefold increase in mean value. While considering the volume of gastric aspirate it ranged from $4-8 \mathrm{ml}$ in omeprazole group with a mean of $5.4 \mathrm{ml}$ which is highly significant). 
One drawback in our study as well as the other studies is that the exact location of the gastric tube cannot be known at the time of collection of gastric contents. Also the completeness of gastric emptying cannot be accurately ascertained. However, the error in estimation of volume of gastric contents was similar in all groups because we use the same standard technique.

Another possible criticism is that the drugs were administered in fixed dosages rather than by body weight and this could theoretically influence the results. This was not found to be true as there were no significant difference seen by modifying the dosages (Manchikanti L 1984). In the present study there was no statistically significant difference in the mean body weight or height of the patients in the three groups.

\section{Summary \& Conclusion}

The effects omeprazole and ranitidine on gastric fluid volume and $\mathrm{pH}$ on patients for elective surgery under general anaesthesia has been compared.

It is proved beyond doubt that both the treatment groups were definitely superior to the control group in increasing the gastric $\mathrm{pH}$ as well as reducing the gastric volume. The gastric $\mathrm{pH}$ showed a 5 times higher $\mathrm{pH}$ value in the patients put on drug regimen than the control. In reducing the gastric volume too, the treatment regimen is superior to control regime. Capsule omeprazole $40 \mathrm{mg}$ at bedtime orally and $40 \mathrm{mg}$ orally on the morning of surgery is found to be an effective adjuvant to safe anaesthetic practice. It should be routinely included in the preanaesthetic preparation of all elective surgical patients undergoing general anaesthesia to prevent the dreaded complications of acid aspiration pneumonitis.

\section{Acknowledgements}

I express my thanks and gratitude to Professor Dr. Sobha $S$ and thankful Dr. Muralikrishnan, Additional Professor, Anesthesiology.

\section{References}

1. Mendelson C.L - The aspiration of stomach contents into the lungs during obstetric anaesthesia. American Journal of Obstetrics and Gynaecology 1946:52:191-205.

2. TEABEAUT J.R (1952) - Aspiration of gastric contents. An experimental study. American Journal of Pathology 28; 51-56.

3. COTTON et al (1981): Single and combined effects of atropine andmetoclopramide on the lower oesophageal sphincter pressure. British Journal of Anaesthesia, 53:869-874.

4. HOLDSWORTH et al (1980): Mixing of antacids with stomach contents- Another approach to the prevention of the acid aspiration (Mendelson's) syndrome. Anaesthesia 1980: 35: 641-650.

5. Manchikanti L, Culliver J A, Marrero TC, Roush JR. Ranitidine and metoclopromide for prophylaxis of aspiration pneumonitis in elective surgery. Anaesthesia and Analgesia 1984;63;703-910.

6. BERTACCINI et al (1981) -.Ranitidine increases the lower oesophageal sphincter pressure in man. Italian Journal of Gastroenterology 13; 149-150.

7. Andrews AD, Buock utne JG, Downing JW. Protection against pulmonary acid aspiration with ranitidine - A new histamine (H2) receptor antagonist Anaesthesia analgesia 1982;61;130132.

8. Lind T Cederberg C, Ekenved G, Haglund U, Olbe L - Effect of Omeprazole- a gastric pump inhibitor on pentagastrin stimulated acid secretion in man GUT 1983:24:270-276.

9. Prichard PJ, Yeomans ND, Mihaly GW, Jones DB, Buckle PJ, Smallwood RA, Louis WJ. Omeprazole - a study of its inhibition of gastric $\mathrm{pH}$ and oral pharmacokinetics after morning or evening dosase. Gastroenterology 1985:88:64-69.

10. Ching MS, Morgan DJ, Mithaly GW, Hardy KJ,Smallwood RA -Placental transfer of omeprazole in maternal and fetal sheep Developmental pharmacology and therapeutics 1986;9;323-331. 